\title{
Gait re-education with Lokomat System in incomplete spinal cord injury in patients older than 65.
}

Mónica Alcobendas (1), Ana Esclarín (1), Carlos Vicario (2), Rosa María Casado (1), Soraya Martín (1), María Nieves Lacasa (1)
(1). Department of Physical Medicine and Rehabilitation. Hospital Nacional Parapléjicos. Toledo. Spain. (2). Department of Orthopedic Surgery. Hospital Nuestra Senora del Prado. Talavera de la Reina. Spain

\section{Introduction.-}

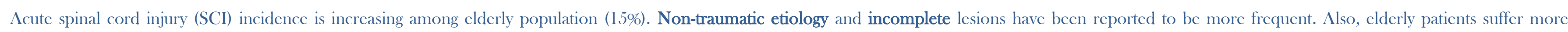
frequently chronic pathology associated. In other hand, increasing age conditionates: impairement of organic functions, worse physical condition, a lower exercise response reserve, and a higher risk of falls.

Lokomat System (LS) is based in the partial weight bearing discharge associated with the use of a treadmill and a robotic device that mobilizates lower extremities. It is included in the group of gait re-education techniques that promote neuronal plasticity.

Intensity / weight bearing inducement and repetitive movements / atention

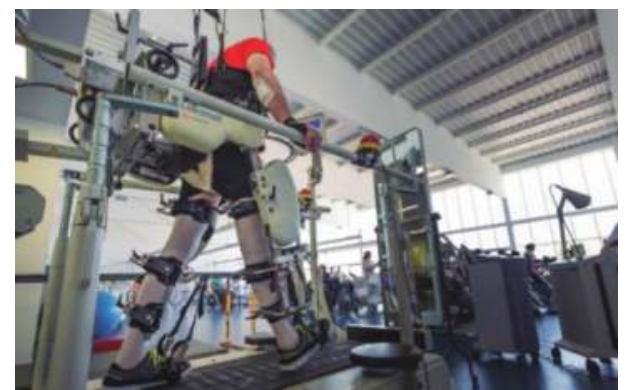

Objetive.-

Advantages: Early initiation, training even if severe paresia is present ,speed and weight bearing can be adapted to individual characteristics of the patient, no overload of upper

extremities.

All of them can produce a benefit also in elderly patients

\section{Method.-}

A prospective and comparative study before and after treatment with LS / Intervention: Forty 30-minute sessions, 5 days per week

Assessment when treatmet was instaured, at a mid point, and at the end.

Statistical analysis with program SPSS 17.0. Paired and independent meand comparison $\mathrm{p} \leq 0,05$

Outcome measures:

Demographic and lesion data / Lower extremity muscle

strength (LEMS) / SCIM II (Spinal cord independence

measure) / WISCI II (Walking Index Spinal Cord Injury)

\section{Inclusion criteria:}

Age: 65 or older / SCI level: C2-L3 / ASIA B-C-D / Less than 6 months of evolution /Develpment of usual program treatment in our institution / Signed informed consent

\section{To determiante effectiveness of Lokomat System $^{\circledR}$ in patients older than 65 diagnosed of Incomplete Spinal Cord Injury}

\section{Results and discussion.-}

49 patients met inclusion criteria in the authors' institution from 2007 to 2016.

Five casses were lost because of reasons not related with the study

\begin{tabular}{|c|c|c|c|c|c|c|c|}
\hline Edad & Sexo & Nivel & & 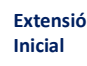 & Final & $\begin{array}{l}\text { Tiempode evolutu } \\
\text { Traumaticita }\end{array}$ & $\begin{array}{l}\text { ción } \\
\text { Médica }\end{array}$ \\
\hline $\begin{array}{l}7,3,705 \\
4,7)\end{array}$ & $\begin{array}{l}32 \\
\text { hombres }\end{array}$ & c1-c8 & 16 & $26 \mathrm{C}$ & $10 \mathrm{c}$ & 130,6 (DS 59,8) & 112,8 (DS 66,1) \\
\hline \multirow{3}{*}{ (65-84) } & 12 mujeres & D1-06 & 7 & $16 \mathrm{D}$ & $33 \mathrm{D}$ & & \\
\hline & & D7-D12 & 15 & $2 B$ & $1 \mathrm{~B}$ & & \\
\hline & & ไ1-13 & 6 & & & & \\
\hline
\end{tabular}

Non traumatic etiology was the most frequent

Comorbidity was very frequent and a high incidence of complications was

reported during the program.

But no complications related with the use of LS were reported.
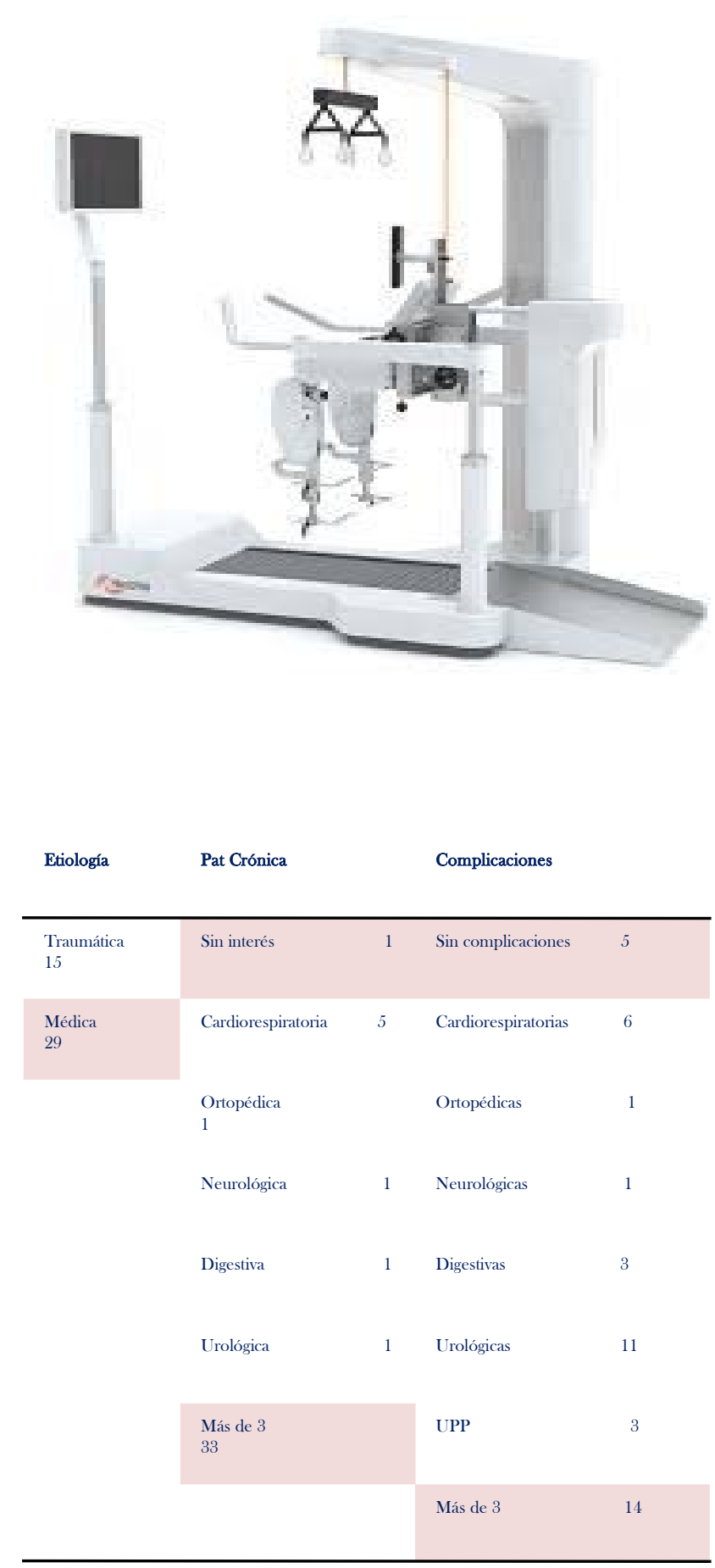

Significative differences were found in every variable analysed with better results if treatment was started 3 or less months after lession.

Functional results were reported as poor, despite high incidence of incomplete SCI, and this finding has been related with previous physical condition, and chronic patholgies commonly associated that hinder physical tratment programs. Longer training times are usually needed in this group of patients.

The high variability in personal conditions in this group of age makes very difficult the development of clinical controlled assays, and adapted programs in time and age are to be developed.

\begin{tabular}{|c|c|c|c|}
\hline & LEMS & SCIM III & WISCI II \\
\hline Inicial & 25 (DS 11,7) & $\begin{array}{l}34,9(\operatorname{DS} 13,8) \\
7,2(\operatorname{DS} 4,2)\end{array}$ & $2,2(\mathbb{D S} 2,3)$ \\
\hline Final & $32,3(11,5)$ & $\begin{array}{l}53,5(\operatorname{DSS} 20,5) \\
14(\operatorname{DSS} 6,7)\end{array}$ & $8,7(\mathbf{D S} 6,6)$ \\
\hline $\mathrm{P}^{*}$ & 0,00 & $\begin{array}{l}0,00 \\
0,00\end{array}$ & 0,00 \\
\hline
\end{tabular}

\begin{tabular}{|c|c|c|c|c|}
\hline Mejoria & $\mathrm{N}$ & LEMS & SCIM III & WISCI II \\
\hline$<90$ dias & 27 & $10,4(\mathrm{DS} 8,5)$ & $9,1(\mathrm{DS} 5,6)$ & $8,7(\mathbf{D S} 7,9)$ \\
\hline$>90$ dias & 17 & $5,3(\mathbf{D S} 5,5,5)$ & $4(\mathrm{DS} 4,7)$ & $5,2(\mathbf{D S} 4,6)$ \\
\hline $\mathrm{P}^{*}$ & & 0,029 & 0,017 & 0,002 \\
\hline
\end{tabular}

\section{Conclusions.-}

Patients older than 65 diagnosed of ISCI are able to complete safely a gait training program with LS .

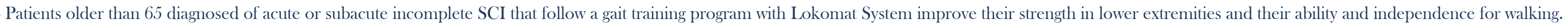
- Probably, basal physical condition and chronic pathologies, frequently associated, are the most important determinants in the low rate found in functional scales.

- Starting treatment 3 or less months after lession is reqalted with an increase of strength, gait ability and independence.

\section{References}

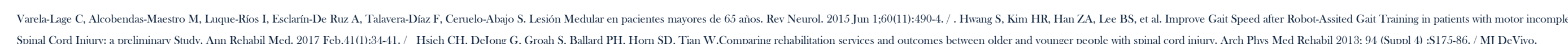

